\title{
A comparison of left ventricular abnormalities associated with glucose intolerance in African Caribbeans and Europeans in the UK
}

\author{
N Chaturvedi, P M McKeigue, M G Marmot, P Nihoyannopoulos
}

\begin{abstract}
Objective-To determine whether abnormalities of the left ventricle differ by glucose tolerance status, to explore reasons for differences, and to assess ethnic differences in these relations.

Design-Population based prevalence study.

Setting-London, UK.

Patients-1152 African Caribbeans and Europeans.

Methods-Echocardiograms, blood pressure, obesity, fasting and two hour blood glucose, insulin and lipids, and urinary albumin excretion rate were measured.

Main outcome measures-Left ventricular mass index, wall thickness, and early (E) to atrial (A) wave ratio.

Results-Left ventricular mass index was greater in diabetic Europeans than in normoglycaemic Europeans (mean (SE), $\left.95.6(5.0) v 79.7(0.8) \mathrm{g} / \mathrm{m}^{2}, \mathrm{p}=0.001\right)$ and in diabetic African Caribbeans than in normoglycaemic African Caribbeans (88.6 (2.5) $v 82.4(0.9) \mathrm{g} / \mathrm{m}^{2}, \mathrm{p}=0.02$ ). Similar, but weaker associations were observed for the E:A ratio. $\beta$ Coefficients between left ventricular mass index and fasting glucose in the normoglycaemic range, adjusted for age and sex, were 2.43 in Europeans $(p=0.05)$ and 3.74 in African Caribbeans $(p=0.02)$. These were attenuated to $1.19(\mathrm{p}=0.4)$ and $3.03(\mathrm{p}=0.08)$ in Europeans and African Caribbeans, respectively, when adjusted further for blood pressure and obesity. Adjustments for other risk factors made little difference to the coefficients. There were no ethnic differences in risk factor relations. Conclusions-Abnormalities of the left ventricle occur in response to glucose intolerance and are observable into the normoglycaemic range. These disturbances are largely accounted for by associated obesity and hypertension. African Caribbeans have a greater degree of left ventricular structural impairment, emphasising the importance of tight blood pressure control.

(Heart 2001;85:643-648)
\end{abstract}

Keywords: echocardiography; glucose tolerance; left ventricular mass index; ethnic differences

Department of Epidemiology and Public Health, University College London, 1-9 Torrington Place, London WC1E 6BT, UK

N Chaturvedi

M G Marmot

Epidemiology and Population Sciences, London School of Hygiene and Tropical Medicine, Keppel Street, London WC1E 7EH, UK P M McKeigue

Cardiology

Department,

Hammersmith

Hospital, Du Cane

Road, London

W12 0HS, UK

P Nihoyannopoulos

Correspondence to: Professor N Chaturvedi, Department of Epidemiology and Public Health, Imperial College at St Mary's, Norfolk Place, London W2 1PG, UK n.chaturvedi@.ic.ac.uk

Accepted 20 February 2001
People with diabetes have a greater risk of morbidity and mortality from cardiovascular disease than the general population, ${ }^{12}$ but the reasons for this remain unclear. One possible explanation is that diabetes may result in structural alterations of the heart, in particular left ventricular hypertrophy, which is itself an independent risk factor for mortality. ${ }^{3}$ In both type 1 and type 2 diabetes, there are claims for a distinct diabetic cardiomyopathy, which occurs even in the absence of ischaemic heart disease and may be responsible for the observed high rates of heart failure in diabetes. ${ }^{5-7}$ However, others argue that concomitant hypertension is mainly responsible for the cardiac changes observed with diabetes. ${ }^{89}$ More recent data indicate that both glucose intolerance and hypertension could contribute to left ventricular hypertrophy through their associations with insulin resistance. ${ }^{10-12}$ If this were the case, we would expect to see consistent ventricular structural changes across the range of glucose tolerance, and not unique changes in the presence of diabetes alone.

People of black African descent are at high risk from both diabetes and raised blood pressure, and are known to have higher rates of stroke and hypertensive heart disease than Europeans. ${ }^{1314}$ However, ischaemic heart disease rates are very low, and we have shown that the adverse cardiovascular risk factor profile observed in Europeans in the presence of glucose intolerance does not occur to the same extent in African Caribbeans. ${ }^{15}$ It is thus clear that risk factor relations observed in one ethnic group may not necessarily be true for others, and that such comparisons between ethnic groups may provide valuable clues about disease aetiology.

With this in mind, we examined the relation between degrees of glucose intolerance and measures of left ventricular structure, as assessed by echocardiography, in a general population sample of European and African Caribbean men and women, and assessed the relative impact of other risk factors in this relation, both within and between ethnic groups.

\section{Methods}

The analyses were performed on data from a cross sectional general population survey of 1166 African Caribbean and European men and women aged 40-64 years. ${ }^{13}$ A detailed description of the methods has been published previously ${ }^{13}{ }^{16}$; in brief, individuals who agreed to take part were invited to attend fasting for a health examination and were asked to complete a questionnaire detailing demographic characteristics, drug treatment, and previous medical history. The study was approved by the relevant ethics committees and written informed consent was obtained from all participants. 
At the examination centre, standardised protocols were used for the measurement of height, weight, and resting blood pressure (determined twice using a random zero Hawksley sphygmomanometer (Lancing, Sussex, UK)). The use of antihypertensive drugs was recorded. A 12 lead ECG was recorded and coded using the Minnesota code. Blood samples were taken fasting and two hours after a $75 \mathrm{~g}$ oral glucose load for measurement of glucose, insulin, total cholesterol, triglyceride, and high density lipoprotein cholesterol. An overnight urine collection was performed for measurement of albumin to calculate albumin excretion rate. This was performed using an in-house immunoturbidimetric method, with antiserum and quality control material from the Supraregional Protein Reference Unit, Sheffield, UK.

ECHOCARDIOGRAPHIC STUDIES

All participants had two dimensional $\mathrm{M}$ mode and Doppler echocardiography performed according to standard procedures. ${ }^{17}$ Left ventricular dimension measures were taken from at least three cycles $^{18}$ and included left ventricular end diastolic diameter (LVEDD), posterior wall thickness, and interventricular septal thickness (all in $\mathrm{mm}$ ). Relative wall thickness and the left ventricular mass index was calculated from the American Society of Echocardiography formula, ${ }^{19}$ the latter indexed to body surface area. Doppler studies were used to measure flow velocity across the mitral valve, and the early (E) to atrial (A) wave ratio (E:A) was calculated. All studies were videotaped, and readings were double checked by one senior observer (PN) who only had access to the identity number of the participant.

STATISTICAL ANALYSES

The mean of the two resting blood pressure measurements was used in all analyses. Results for systolic and diastolic blood pressure were similar, and we have therefore only presented the systolic blood pressure analyses. Diabetes and impaired glucose tolerance was diagnosed according to the previous World Health Organization criteria ${ }^{20}$ which were current at the time of the study. Analyses were repeated using the newer classification ${ }^{21}$ and the results did not differ. All subjects with evidence of a previous myocardial infarct and all those on treatment for hypertension were included in the analyses, comparing echocardiographic variables by glucose tolerance category, as we wished to determine whether differences existed in a representative sample of the general population which might, for whatever reason, explain population levels of disease. As the majority of people with known diabetes are on antihypertensive treatment, excluding these from the analysis could result in the comparison of a biased and certainly unrepresentative population. We have previously shown that calculated left ventricular mass index may be misleading when comparing different ethnic groups, as the structural response to raised blood pressure may be very different. ${ }^{16}{ }^{19}$ In this paper we therefore present associations with component measures as well as with mass index itself. Mean values for echocardiographic variables were calculated using multiple regression techniques, with ethnic group and glucose tolerance as the predictor variables adjusted for age and sex. Interactions between ethnic group and glucose tolerance status were also tested. Pearson correlation coefficients were estimated for variables associated with insulin resistance, again stratified by ethnic group. Skewed variables such as insulin, triglyceride, and albumin excretion rate were $\log$ transformed for analysis.

The second level of analysis was designed to explore reasons for a relation between circulating glucose and echocardiographic abnormalities. For these analyses, we wished to ensure that potential risk factors had not been modified by the glucose intolerant state or that outcomes (echocardiographic measures) had been altered by disease or treatment. Thus these latter analyses are restricted to normoglycaemic individuals only, and those with evidence of myocardial infarction on ECG or on antihypertensive treatment were excluded from the analysis. $\beta$ Coefficients for fasting glucose in multiple regression models, again stratified by ethnicity, are reported. Changes in this coefficient following the addition of confounding variables such as blood pressure and body mass index indicate how much of the relation between glucose and an echocardiographic variable can be accounted for by confounders. Analyses were performed separately for men and women first, and as there were no appreciable sex differences in risks and risk factor relations, the sexes have been combined for presentation.

Glucose intolerance status could not be assigned to nine individuals, so the association between glucose intolerance and echocardiographic indices was restricted to 1157 of 1166 patients (582 Europeans and 575 African Caribbeans). In those who were potentially eligible for the normoglycaemic analyses, 18 had evidence of a previous myocardial infarct on ECG, and 119 were on antihypertensive treatment. Thus those analyses were performed on 757 of 894 participants.

\section{Results}

In general, echocardiographic measures of structure were worse for people with known diabetes compared with normoglycaemic individuals (table 1), although this comparison reached significance in both ethnic groups for both the wall thickness measurements and the left ventricular mass index only. Tests for trend across the range of glucose intolerance showed statistical significance for both ethnic groups for posterior wall thickness and the E:A ratio. However, even a comparison of normoglycaemic individuals and those with impaired glucose tolerance showed important differences, especially for African Caribbeans, where interventricular septal thickness, posterior wall thickness, E:A ratio, relative wall thickness, and LVEDD all differed significantly. Less strong associations were observed 
Table 1 Echocardiographic measures of structure and function by glucose tolerance status and ethnic group (adjusted for age and sex)

\begin{tabular}{|c|c|c|c|c|c|c|c|c|c|}
\hline \multirow[b]{2}{*}{ Variable } & \multicolumn{5}{|c|}{ Glucose tolerance category } & \multirow[b]{2}{*}{ p Trend } & \multirow{2}{*}{$\begin{array}{l}p \text { Value for } \\
D M v N G\end{array}$} & \multirow{2}{*}{$\begin{array}{l}p \text { Value for } \\
I G T v N G\end{array}$} & \multirow{2}{*}{$\begin{array}{l}p \text { Value for } \\
\text { ethnicity }\end{array}$} \\
\hline & Normoglycaemic & $I G T$ & & New DM & Known DM & & & & \\
\hline European (n) & 499 & 53 & & 15 & 15 & & & & \\
\hline African Caribbean (n) & 395 & 90 & & 33 & 57 & & & & \\
\hline \multicolumn{10}{|c|}{ Left ventricular end diastolic diameter $(\mathrm{mm})$} \\
\hline European & $45.8 \quad(0.2)$ & 46.9 & $(0.6)$ & $44.1(1.2)$ & $47.2(1.2)$ & 0.4 & 0.3 & 0.1 & \\
\hline African Caribbean & $45.3(0.2)$ & 43.9 & $(0.5)$ & $44.8 \quad(0.8)$ & $44.9 \quad(0.6)$ & 0.06 & 0.5 & 0.008 & 0.01 \\
\hline \multicolumn{10}{|c|}{ Interventricular septal thickness ( $\mathrm{mm}$ ) } \\
\hline European & $9.5(0.1)$ & 9.6 & $(0.2)$ & $9.7(0.4)$ & $10.3(0.4)$ & 0.2 & 0.04 & 0.8 & \\
\hline African Caribbean & $10.0 \quad(0.1)$ & 10.7 & $(0.2)$ & $10.2(0.3)$ & $10.6 \quad(0.2)$ & 0.002 & 0.02 & 0.005 & 0.0005 \\
\hline \multicolumn{10}{|c|}{ Posterior wall thickness ( $\mathrm{mm}$ ) } \\
\hline European & $9.2(0.1)$ & 9.5 & $(0.2)$ & $9.2(0.4)$ & $10.1(0.4)$ & 0.02 & 0.01 & 0.06 & \\
\hline African Caribbean & $9.6 \quad(0.1)$ & 10.0 & $(0.2)$ & $9.8 \quad(0.2)$ & $10.1 \quad(0.2)$ & 0.01 & 0.01 & 0.008 & 0.03 \\
\hline \multicolumn{10}{|l|}{ E: $A$ ratio } \\
\hline European & $1.26(0.02)$ & 1.09 & $(0.06)$ & $1.22(0.11)$ & $1.14(0.10)$ & 0.05 & 0.3 & 0.008 & \\
\hline African Caribbean & $1.14(0.02)$ & 0.98 & $3(0.03)$ & $1.02(0.07)$ & $1.00(0.05)$ & 0.0001 & 0.003 & 0.001 & 0.007 \\
\hline \multicolumn{10}{|l|}{ Relative wall thickness } \\
\hline European & $0.41(0.003)$ & 0.41 & $(0.01)$ & $0.42(0.02)$ & $0.44(0.02)$ & 0.3 & 0.09 & 0.4 & \\
\hline African Caribbean & $0.43(0.005)$ & 0.47 & $7(0.01)$ & $0.44(0.01)$ & $0.46(0.01)$ & 0.004 & 0.03 & 0.001 & 0.004 \\
\hline \multicolumn{10}{|c|}{ Left ventricular mass index $\left(\mathrm{g} / \mathrm{m}^{2}\right)$} \\
\hline European & $79.7 \quad(0.8)$ & 84.5 & $(2.5)$ & $77.4 \quad(4.8)$ & $95.6(5.0)$ & 0.004 & 0.001 & 0.07 & \\
\hline African Caribbean & $82.4 \quad(0.9)$ & 83.4 & $(1.9)$ & $83.8(3.3)$ & $88.6 \quad(2.5)$ & 0.2 & 0.02 & 0.6 & 0.9 \\
\hline
\end{tabular}

Values are mean (SE).

DM, diabetes mellitus; E:A, ratio of early (E) to atrial (A) wave; IGT, impaired glucose tolerance; NG, normoglycaemic.

for Europeans. Throughout, African Caribbeans tended to have a more adverse echocardiographic profile than Europeans (apart from LVEDD). Tests for an ethnic group interaction comparing glucose intolerant and normoglycaemic individuals were significant for LVEDD ( $p=0.003)$ and interventricular septal thickness $(p=0.02)$, and approached significance for relative wall thickness (0.06). This ethnic difference in the impact of impaired glucose tolerance on echocardiographic variables is reflected in the difference in resting systolic blood pressure between normoglycaemic individuals and those with impaired glucose tolerance- $1 \mathrm{~mm} \mathrm{Hg}$ in Europeans and $5 \mathrm{~mm} \mathrm{Hg}$ in African Caribbeans $(\mathrm{p}=0.0001)$.

In normoglycaemic individuals with no evidence of a previous myocardial infarct and not on antihypertensive treatment, there were strong correlations between fasting glucose and echocardiographic variables (table 2). Results for posterior wall thickness were similar to those for interventricular septal thickness and for clarity are not shown here. Associations were also observed with fasting insulin, lipids, and albumin excretion rate, but these were generally stronger for Europeans than for African Caribbeans. In both ethnic groups, very strong associations were observed between measures of obesity and blood pressure and the echocardiographic measures.

$\beta$ Coefficients were calculated between fasting glucose and echocardiographic measures for this group of normoglycaemic individuals (table 3). In both ethnic groups, strong coefficients were observed for measures of wall thickness and left ventricular mass index, even when adjusted for age and sex. These associations were largely attenuated by the addition of resting systolic blood pressure and body mass

Table 2 Correlation coefficients between echocardiographic measures of structure and function by ethnic group in normoglycaemic individuals (excluding those with a previous myocardial infarct or on antihypertensive treatment)

\begin{tabular}{|c|c|c|c|c|c|}
\hline & LVEDD & IVS & $E: A$ & $R W T$ & $L V M I$ \\
\hline \multicolumn{6}{|l|}{ Europeans $(n=452)$} \\
\hline Age & -0.4 & $0.19^{\star \star \star}$ & $-0.42^{\star \star \star}$ & $0.20^{\star \star \star}$ & $0.16^{\star \star \star}$ \\
\hline Systolic blood pressure & $0.17^{\star \star \star}$ & $0.33^{\star \star \star}$ & $-0.28^{\star \star \star}$ & $0.11^{\star}$ & $0.27^{\star \star \star}$ \\
\hline Fasting glucose & $0.13^{\star \star}$ & $0.21^{\star \star \star}$ & -0.06 & $0.12^{\star}$ & $0.17^{\star \star \star}$ \\
\hline Fasting insulin & $0.18^{\star \star \star}$ & -0.03 & $-0.13^{\star \star}$ & $-0.15^{\star \star}$ & -0.03 \\
\hline BMI & $0.30^{\star \star \star}$ & $0.20^{\star \star \star}$ & $-0.19^{\star \star \star}$ & -0.05 & $0.11^{\star}$ \\
\hline Waist circumference & $0.50^{\star \star \star}$ & $0.33^{\star \star \star}$ & $-0.21^{\star \star \star}$ & -0.05 & $0.24^{\star \star \star}$ \\
\hline Albumin excretion rate & $0.15^{\star \star}$ & $0.16^{\star \star \star}$ & 0.05 & 0.07 & $0.17^{\star \star \star}$ \\
\hline Fasting triglyceride & $0.17^{\star \star \star}$ & $0.16^{\star \star \star}$ & $-0.14^{\star \star}$ & 0.02 & $0.15^{\star \star}$ \\
\hline \multicolumn{6}{|c|}{ African Caribbeans $(n=305)$} \\
\hline Age & 0.03 & $0.15^{\star \star}$ & $-0.44^{\star \star \star}$ & 0.08 & $0.20^{\star \star \star}$ \\
\hline Systolic blood pressure & 0.01 & $0.13^{\star}$ & $-0.20^{\star \star \star}$ & 0.09 & $0.11^{\star}$ \\
\hline Fasting glucose & $0.17^{\star \star}$ & $0.15^{\star \star}$ & $-0.14^{\star}$ & 0.06 & $0.20^{\star \star \star}$ \\
\hline Fasting insulin & 0 & 0.05 & -0.07 & 0.04 & 0 \\
\hline BMI & 0.05 & $0.11^{\star}$ & -0.11 & 0.07 & -0.04 \\
\hline Waist circumference & $0.24^{\star \star \star}$ & $0.26^{\star \star \star}$ & $-0.17^{\star \star}$ & 0.07 & $0.14^{\star}$ \\
\hline Albumin excretion rate & 0 & $0.12^{\star}$ & 0.04 & 0.12 & 0.09 \\
\hline Fasting triglyceride & 0.06 & 0.06 & $-0.17^{\star \star}$ & 0.02 & 0.03 \\
\hline
\end{tabular}

${ }^{\star} \mathrm{p}<0.05 ;{ }^{\star \star} \mathrm{p}<0.01 ;{ }^{\star \star \star} \mathrm{p}<0.001$

BMI, body mass index; E:A, early (E) to atrial (A) wave ratio; IVS, interventricular septal thickness; LVEDD, left ventricular end diastolic diameter; LVMI, left ventricular mass index; RWT, relative wall thickness. 
Table $3 \quad \beta$ Coefficients and p values for fasting glucose by ethnic group (normoglycaemic only, with no history of myocardial infarction or antihypertensive treatment)

\begin{tabular}{|c|c|c|c|c|}
\hline \multirow{2}{*}{$\begin{array}{l}\text { Model } \\
\text { variables }\end{array}$} & \multicolumn{2}{|c|}{$\begin{array}{l}\text { European } \\
(n=452)\end{array}$} & \multicolumn{2}{|c|}{$\begin{array}{l}\text { African Caribbean } \\
(n=305)\end{array}$} \\
\hline & $\beta$ & $p$ Value & $\beta$ & $p$ Value \\
\hline \multicolumn{5}{|c|}{ Left ventricular end diastolic diameter } \\
\hline Age, sex & 0.14 & 0.6 & 0.71 & 0.1 \\
\hline$+\mathrm{BP}$ & -0.02 & 0.9 & 0.70 & 0.1 \\
\hline$+\mathrm{BP}+\mathrm{BMI}$ & -0.44 & 0.2 & 0.41 & 0.4 \\
\hline \multicolumn{5}{|c|}{ Interventricular septal thickness } \\
\hline Age, sex & 0.31 & 0.002 & 0.28 & 0.07 \\
\hline$+\mathrm{BP}$ & 0.20 & 0.04 & 0.24 & 0.1 \\
\hline$+\mathrm{BP}+\mathrm{BMI}$ & 0.15 & 0.1 & 0.14 & 0.4 \\
\hline \multicolumn{5}{|c|}{ Posterior wall thickness } \\
\hline Age, sex & 0.32 & 0.0003 & 0.34 & 0.02 \\
\hline$+\mathrm{BP}$ & 0.26 & 0.004 & 0.31 & 0.03 \\
\hline$+\mathrm{BP}+\mathrm{BMI}$ & 0.23 & 0.01 & 0.21 & 0.1 \\
\hline \multicolumn{5}{|l|}{ E:A ratio } \\
\hline Age, sex & -0.02 & 0.5 & -0.07 & 0.02 \\
\hline$+\mathrm{BP}$ & 0.01 & 0.8 & -0.06 & 0.04 \\
\hline$+\mathrm{BP}+\mathrm{BMI}$ & 0.02 & 0.4 & -0.05 & 0.1 \\
\hline \multicolumn{5}{|c|}{ Relative wall thickness } \\
\hline Age, sex & 0.01 & 0.007 & 0.01 & 0.3 \\
\hline$+\mathrm{BP}$ & 0.01 & 0.02 & 0.01 & 0.3 \\
\hline$+\mathrm{BP}+\mathrm{BMI}$ & 0.01 & 0.004 & 0.01 & 0.5 \\
\hline \multicolumn{5}{|c|}{ Left ventricular mass index } \\
\hline Age, sex & 2.43 & 0.05 & 3.74 & 0.02 \\
\hline$+\mathrm{BP}$ & 1.43 & 0.3 & 3.39 & 0.02 \\
\hline$+\mathrm{BP}+\mathrm{BMI}$ & 1.19 & 0.4 & 3.03 & 0.08 \\
\hline
\end{tabular}

$\mathrm{BMI}$, body mass index; BP, blood pressure; E:A ratio, early (E) to atrial (A) wave ratio.

index into the model, reducing the $\beta$ coefficient by one third to one half. Further addition of other variables - such as insulin, albumin excretion rate, lipids, and other measures of obesity-did not materially alter the $\beta$ coefficients. In general, the magnitude of the $\beta$ coefficients and the impact of adjustment for various confounders were similar for the two ethnic groups.

\section{Discussion}

In this population based study, with a wide range of blood glucose concentrations, we show that people with diabetes have abnormalities of the left ventricle compared with their normoglycaemic counterparts, and that this applies equally to both Europeans and African Caribbeans. These differences are particularly pronounced for measures of wall thickness and the composite measure of left ventricular mass index. We further show that the differences are present even at the impaired glucose tolerance stage, where drug treatment is unlikely to have altered the echocardiographic indices.

Several other studies have shown an increase in interventricular septal thickness with glucose intolerance or diabetes in women only ${ }^{622}$ or in both sexes combined. ${ }^{24}$ One showed no association $^{25}$ and one showed a difference only between controls and patients with diabetic complications. ${ }^{26}$ LVEDD is not usually raised in the glucose intolerant state, ${ }^{23-25} 27{ }^{28}$ but some investigators have found an increase $^{6}$ or a reduction in LVEDD with glucose intolerance. ${ }^{22}{ }^{26}$ Left ventricular mass index is also generally found to be raised in the diabetic state in women only, ${ }^{622} 23$ or in both sexes. ${ }^{112429}$
No differences were found between diabetic individuals and controls in two studies. ${ }^{26} 30$

The disparate findings from previous studies could be accounted for in various ways. Several of the studies had relatively small numbers and may have been underpowered for some of the comparisons. ${ }^{24} 26$ Patient selection could be another factor, as several excluded patients with varying degrees of pre-existing heart disease or hypertension, ${ }^{24252630}$ and this may introduce bias if these conditions are not equally distributed in the comparator groups. Further, as we have previously shown, the structural response to an insult may differ by ethnicity, ${ }^{16}$ in particular for LVEDD. These different responses, which may be determined by factors other than ethnicity, could be the reason why left ventricular mass index (which is a composite of LVEDD and wall thickness measurements) may be higher in some glucose intolerant populations compared with controls while not differing in others. The use of composite measures of echocardiography to compare left ventricular hypertrophy between ethnic groups has rightly been criticised for this reason. ${ }^{31}$

Most of these previous studies have been confined to people with diabetes. In the present study we show a dose-response relation for interventricular septal thickness across a wide range of blood glucose in the general population. Further, we found that there was a strong correlation between fasting glucose and echocardiographic indices even in normoglycaemic individuals, such that increasing glucose intolerance in the normoglycaemic range was positively associated with obesity and blood pressure. Adjusting for any measure of blood pressure and for obesity greatly attenuated the relation between glucose and left ventricular hypertrophy. In general, the $\beta$ coefficients were reduced by about one third to one half, supporting previous findings. ${ }^{24} 32$ However, adjustment for blood pressure alone could not wholly abolish the observed association between glycaemia and echocardiographic measures of structure. A single measurement of blood pressure and obesity can only begin to approximate lifetime exposure to these two risk factors. If it were possible to include "perfect" measures of these variables in our multivariate model, it is likely that the $\beta$ coefficients for the impact of glucose on echocardiographic measures would be attenuated still further, and we therefore suggest that the greatest part of the association between glucose and left ventricular abnormalities can largely be explained by associated changes in blood pressure and obesity.

Other factors that may account for the relation between glucose and interventricular septal thickness in these data were albumin excretion rate, insulin, and triglyceride concentrations. Others have shown that the presence of diabetic complications further increases structural damage to the left ventricle. ${ }^{24}{ }^{26}$ The reasons for this increased damage are unclear, but again it is most likely to reflect disturbances in the other risk factors, particularly blood pressure. $^{24}$ We show that adjustment for albumin excretion rate over blood pressure had 
no appreciable impact on the $\beta$ coefficients. Similarly, although others have indicated the importance of insulin resistance in determining left ventricular hypertrophy, ${ }^{10} 1233$ in this study, insulin and triglyceride did not contribute significantly to the model in multivariate analysis and were therefore excluded from the final models. It is likely, however, that the impact of insulin resistance on left ventricular hypertrophy is mediated through hypertension and obesity, so it is perhaps not surprising that insulin has little effect in a model that already contains these two risk factors.

Nevertheless, there may be other factors associated with hyperglycaemia that contribute to left ventricular structural abnormalities. One way in which chronic hyperglycaemia expresses its toxicity is to form non-enzymatic glycation of tissue macromolecules such as proteins, lipids, and DNA to form irreversibly bound advanced glycation end products. ${ }^{34}$ Such products have been found to accumulate in tissues such as the heart in the presence of diabetes. ${ }^{35}$ These may cause oxidative damage directly, or indirectly through stimulation of cytokines.

Across the spectrum of glucose intolerance, African Caribbeans in general have a worse echocardiographic profile than Europeans. There were indications that abnormalities in glucose intolerant individuals were greater in African Caribbeans than in Europeans, particularly for LVEDD and interventricular septal thickness. This greater impact of glucose intolerance on left ventricular indices probably reflects the higher blood pressures observed in African Caribbeans. Very few studies have examined people of black African descent in this context. Of those that have, a study of Nigerians found interventricular septal thickness and left ventricular mass index to be higher in diabetic than non-diabetic subjects, but this difference was much smaller than the difference between normotensive and hypertensive individuals. ${ }^{36}$ Further, the combination of both diabetes and hypertension did not appear to be worse than hypertension itself. In a UK based study, variations in wall thickness were examined in relation to serum creatinine in diabetic patients. ${ }^{27}$ It was found that wall thickness was greater in African Caribbeans than in Europeans, ${ }^{27}$ as in the present study. The reasons for these differences - in particular the role of blood pressure-were not explored.

\section{CONCLUSIONS}

Thus there is little evidence for a distinct effect of diabetes on the left ventricle, but instead there is evidence of an association with left ventricular hypertrophy across the range of blood glucose concentrations and well into the normoglycaemic range. These associations can largely be accounted for by blood pressure and obesity. There is a link between left ventricular structure and measures of insulin resistance, but this can be accounted for by obesity and blood pressure. While African Caribbeans appear more likely to have left ventricular abnormalities associated with glucose intolerance, this probably reflects the higher blood pressures observed in this group and it emphasises the importance of good blood pressure control in this population.

This study was supported by a programme grant from the UK Medical Research Council. We are grateful to the Jeffrey Kelson Diabetic Centre, Central Middlesex Hospital, and Wembley Stadium Medical Centre for accommodation; family practices Talbot Walk for providing patient lists; Advanced Technology Talbot Walk for providing patient lists; Advanced Technology
Laboratories, Letchworth, UK for the echocardiographic equipment; Smith Kline Beecham for the glucose drink; all equipment; Smith Kline Beecham for the glucose drin
members of the project team and all those who took part.

1 Stamler J, Vaccaro O, Neaton JD, et al. Diabetes, other risk factors, and 12-yr cardiovascular mortality for men screened in the multiple risk factor intervention trial. Diabetes Care 1993;16:434-44.

2 Kannel WB, McGee DL. Diabetes and cardiovascular disease. $7 A M A 1979 \cdot \mathbf{2 4 1} \cdot 2035$

3 Kannel WB, Hjortland M, Castelli WP. Role of diabetes in congestive heart failure. Am $\mathcal{f}$ Cardiol 1974;34:29-34.

4 Levy D, Garrison RJ, Savage DD, et al. Prognostic implications of echocardiographically determined left ventricular tions of echocardiographically determined left ventricular
mass in the Framingham study. N Engl f Med 1990;322: mass in

5 Sanderson JE, Brown DDJ, Rivellese A, et al. Diabetic cardiomyopathy? An echocardiographic study of young diabetics. BMF 1978;i:404-7.

6 Galderisi M, Anderson KM, Wilson PWF, et al. Echocardiographic evidence for the existence of distinct diabetic cardiomyopathy. Am f Cardiol 1991;68:85-9.

7 Danielsen R, Nordrehaug JE, Lien E, et al. Subclinical left ventricular abnormalities in young subjects with long-term diabetes mellitus detected by digitized $\mathrm{M}$-mode echocardiography. Am f Cardiol 1987;60:143-6.

8 Factor SM, Minase T, Sonnenblick EH. Clinical and morphological features of human hypertensive-diabetic cardiomyopathy. Am Heart f 1980;99:446-58.

9 Danielsen R. Factors contributing to left ventricular diastolic dysfunction in long-term type 1 diabetic subjects. Acta Med Scand 1988;224:249-56.

10 Rheeder P, Stolk RP, Mosterd A, et al. Insulin resistance syndrome and left ventricular mass in an elderly population syndrome and left ventricular mass in an elderly popul
(the Rotterdam study). Am f Cardiol 1999;84:233-6.

11 Lee M, Gardin JM, Lynch JC, et al. Diabetes mellitus and echocardiographic left ventricular function in free-living elderly men and women: the Cardiovascular Health Study. Am Heart 7 1997;133:36-43.

12 Sasson Z, Rasooly Y, Bhesania T, et al. Insulin resistance is an important determinant of left ventricular mass in the obese. Circulation 1993;88:1431-6.

13 Chaturvedi N, McKeigue PM, Marmot MG. Resting and ambulatory blood pressure differences in Afro-Caribbeans and Europeans. Hypertension 1993;22:90-6.

14 Wild S, McKeigue P. Cross sectional analysis of mortality by country of birth in England and Wales, 1970-92. BMf 1997;314:705-10.

15 Chaturvedi N, McKeigue PM, Marmot MG. Relationship of glucose intolerance to coronary risk in Afro-Caribbeans compared with Europeans. Diabetologia 1994;37:765-72.

16 Chaturvedi N, Athanassopoulos G, McKeigue PM, et al. Echocardiographic measures of left ventricular structure and their relationship with resting and ambulatory blood pressure in Afro-Caribbeans and Europeans in the UK. $\mathcal{F}$ Am Coll Cardiol 1994;24:1499-505.

17 Devereux RB, Liebson PR, Horan MJ. Recommendations concerning use of echocardiography in hypertension and general population research. Hypertension 1987;9(suppl II): $97-104$

18 Sahn DJ, DeMaria A, Kisslo J, et al. Recommendations regarding quantitation in $\mathrm{M}$-mode electrocardiography: results of a survey of echocardiographic measurements. Circulation 1978;58:1072-83.

19 Devereux RB, Alonso DR, Lutas EM, et al. Echocardiographic assessment of left ventricular hypertrophy: comparison to necropsy findings. Am 7 Cardiol 1986;57:450-8.

20 World Health Organisation Study Group on Diabetes Mellitus. Diabetes mellitus (WHO technical report series No. 727). Geneva: WHO, 1985:1-113.

21 Alberti KGMM, Zimmet PZ. Definition, diagnosis and classification of diabetes mellitus and its complications. Part 1. Diagnosis and classification of diabetes mellitus, provisional report of a WHO consultation. Diabet Med provisional report

22 Uusitupa M, Mustonen J, Laakso M, et al. Impairment of diastolic function in middle-aged type 1 (insulindependent) and type 2 (non-insulin-dependent) diabetic patients free of cardiovascular disease. Diabetologia 1988; 31:783-91.

23 Uusitupa M, Siitonen O, Pyorala K, et al. Left ventricular function in newly diagnosed non-insulin-dependent (type 2) diabetics evaluated by systolic time intervals and echocardiography. Acta Med Scand 1985;217:379-88.

24 Nielsen FS, Ali S, Rossing P, et al. Left ventricular hypertrophy in non-insulin-dependent diabetic patients with and without diabetic nephropathy. Diabet Med 1997;14:53846.

25 Shapiro LM, Howat AP, Calter MM. Left ventricular function in diabetes mellitus. I. Methodology and prevalence and spectrum of abnormalities. Br Heart f 1981;45:122-8.

26 Airaksinen J, Ikaheimo M, Kaila J, et al. Impaired left ventricular filling in young female diabetics. An echocardiographic study. Acta Med Scand 1984;216:509-16. 
27 Grenfell A, Monaghan M, Watkins PJ, et al. Cardiac hypertrophy in diabetic nephropathy: an echocardiographic

28 Zoneraich S, Zoneraich O, Rhee JJ. Left ventricular performance in diabetic patients without clinical heart disease. Evaluation by systolic time intervals and echocardiography. Chest 1977;72:748-51.

29 Jain A, Avendano G, Dharamsey S, et al. Left ventricular diastolic function in hypertension and role of plasma glucose and insulin. Comparison with diabetic heart. Circulation 1996;93:1396-402.

30 Sampson MJ, Denver E, Foyle WJ, et al. Association between left ventricular hypertrophy and erythrocyte sodium-lithium exchange in normotensive subjects with and without NIDDM. Diabetologia 1995;38:454-60.

31 Watkins LO. Impact on interracial comparisons of inappropriate criteria for cardiac enlargement in blacks. Hyperpriate criteria for cardiac
32 Grossman E, Shemesh J, Shamiss A, et al. Left ventricular mass in diabetes-hypertension. Arch Intern Med 1992;152: mass in

33 Verdecchia P, Reboldi G, Schillaci G, et al. Circulating insulin and insulin growth factor-1 are independent determinants of left ventricular mass and geometry in essential hypertension. Circulation 1999;100:1802-7.

34 Brownlee M. Advanced protein glycosylation in diabetes and aging. Annu Rev Med 1995;46:223-34.

35 Schleicher ED, Wagner E, Nerlich AG. Increased accumulation of the glycoxidation product N-epsilon-(carboxymethyl) lysine in human tissues in diabetes and aging. 7 Clin Invest 1997;99:457-68.

36 Babalola RO, Ajayi AA. A cross-sectional study of echocardiographic indices, treadmill exercise capacity and microvascular complications in Nigerian patients with hypertension associated with diabetes mellitus. Diabet Med 1992; 9:899-903.

\section{IMAGES IN CARDIOLOGY}

\section{Coronary arterial-left ventricular fistulae}

A 64 year old woman presented with a six month history of progressive exertional dyspnoea and paroxysmal nocturnal dyspnoea. Echocardiography showed severe pulmonary hypertension, concentric left ventricular hypertrophy, normal systolic function, and no evidence of shunting by saline contrast. The 12 lead ECG exhibited atrial fibrillation. Chest radiography and computed tomography (CT) revealed dilated proximal pulmonary arteries without signs of parenchymal lung disease or pulmonary venous abnormalities.

Cardiac catheterisation showed fixed pulmonary hypertension without shunting. Selective coronary angiography demonstrated tortuous, dilated, epicardial coronary arteries (below left) with all three coronary arteries draining into the left ventricle via a diffuse plexus of coronary fistulae. Left coronary angiography (late frame) revealed diastolic opacification of the left ventricle (below right). The coronary sinus was not cannulated during right heart catheterisation, and there was no obvious

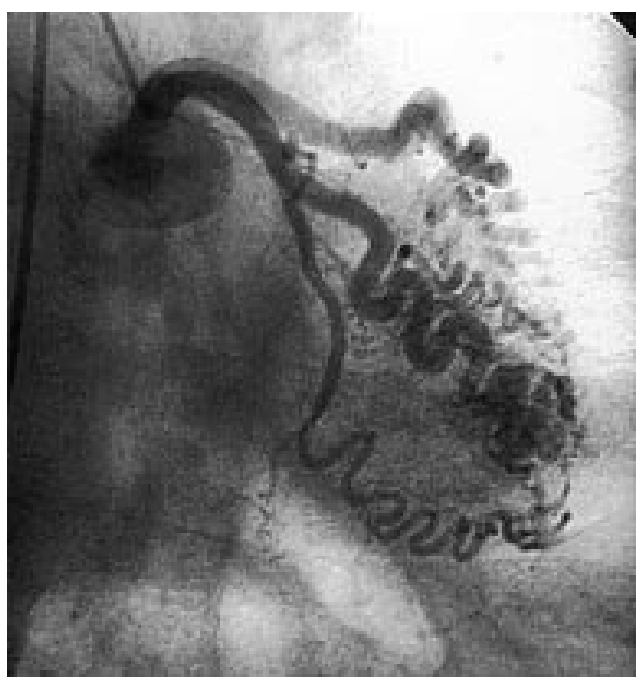

opacification of it in the delayed phase of coronary angiogram.

Coronary artery fistulae between a coronary artery and a cardiac chamber can occur in $0.2 \%$ of diagnostic cardiac catheterisations and usually arise from the right coronary artery to drain into a right heart structure (right atrium, right ventricle or pulmonary artery). Fistulae draining into the left ventricle are uncommon, with less than 20 reported cases of fistulae involving all three coronary arteries. These congenital fistulae are abnormally prominent Thebesian vessels that represent persistence of the intertrabecular vascular network. They result in a diastolic volume overload of the left ventricle (left-to-left shunt), dilated epicardial arteries, and a "coronary steal" with shunting of blood away from the myocardium into the low resistance fistulae.

HAITHAM AMIN NARESH SOLANKHI ORHAN UZUN orhanuzun@hotmail.com

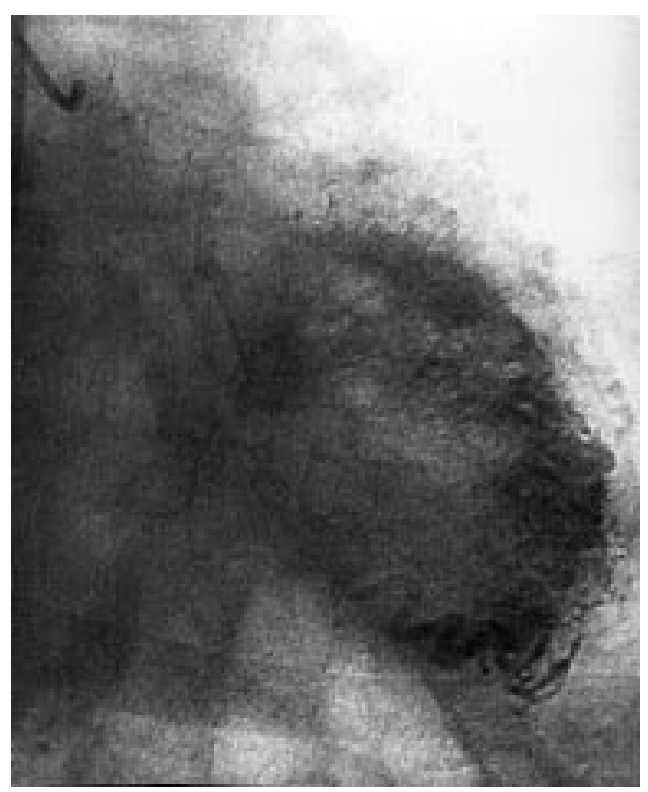

